\title{
Microinjection of IL-1 $\beta$ into the Trigeminal Transition Zone Produces Bilateral NMDA Receptor-Dependent Orofacial Hyperalgesia Involving Descending Circuitry
}

\author{
K. Shimizü, Bryan Chai", Stacey C. LaGraize, F. Wei, R. Dubner and K. Ren*
}

Department of Neural and Pain Sciences, Dental School, \& Program in Neuroscience, University of Maryland, Baltimore, MD 21201, USA

\begin{abstract}
Our recent studies indicate that the prototypic proinflammatory cytokine IL-1 $\beta$ is upregulated in astroglial cells in the trigeminal interplolaris/caudalis $(\mathrm{Vi} / \mathrm{Vc})$ transition zone, a region of the spinal trigeminal complex involved in trigeminal pain processing, after masseter muscle inflammation. Here we investigated the effect of microinjection of IL$1 \beta$ into the $\mathrm{Vi} / \mathrm{Vc}$ transition zone on orofacial nociception. The mechanical sensitivity of the orofacial site was assessed with von Frey microfilaments. The $\mathrm{EF}_{50}$ values, defined as the von Frey filament force $(\mathrm{g})$ that produces a $50 \%$ response frequency, were derived and used as a measure of mechanical sensitivity. A significant reduction in $\mathrm{EF}_{50}$ indicates the occurrence of mechanical hyperalgesia/allodynia. Unilateral intra-Vi/Vc IL-1 $\beta$ (0.016-160 fmol) produced hyperalgesia/allodynia dose-dependently, which appeared at bilateral facial sites. The hyperalgesia was detectable as early as $30 \mathrm{~min}$ and lasted for $2-6 \mathrm{~h}(\mathrm{n}=6, \mathrm{p}<0.01)$. Intra-Vi/Vc pretreatment with an IL-1receptor antagonist $(1 \mathrm{nmol})$ attenuated the IL-1 $\beta$-induced hyperalgesia ( $\mathrm{p}<0.01)$. Pre-injection of AP-5 (10 pmol) and MK-801 (20 pmol), two NMDA receptor antagonists, significantly attenuated IL-1 $\beta$-induced hyperalgesia $(\mathrm{p}<0.05)$. Pretreatment with glial inhibitors fluorocitrate $(120 \mathrm{pmol})$, minocycline $(200 \mathrm{pmol})$ and propentofylline $(10 \mathrm{pmol})$ did not attenuate IL- $1 \beta$-induced hyperalgesia. Excitotoxic lesions of the rostral ventromedial medulla with ibotenic acid $(2 \mu \mathrm{g})$ abolished IL- $1 \beta$-induced contralateral hyperalgesia, suggesting a contribution of descending facilitatory drive. These results suggest that the IL-1 $\beta$ produced effect on nociception was downstream to glial activation and involves interaction with NMDA receptors.
\end{abstract}

Keywords: Spinal trigeminal complex, Vi/Vc, NMDA receptor antagonists, Inflammatory cytokine, Glial inhibitors, Rat.

\section{INTRODUCTION}

The inflammatory cytokines are among a group of chemical mediators that can be released by activated glia and have been implicated in persistent pain states [1]. Interleukin (IL)- $1 \mathrm{~b}$, a prototype proinflammatory cytokine, is involved in a variety of diseases with pain conditions such as rheumatoid arthritis, inflammatory bowel disease, osteroarthritis, multiple sclerosis and neuropathy [2-4]. We have recently shown that glia-cytokine-neuronal interactions play an important role in activity-dependent plasticity and hyperalgesia [5].

Although peripheral cytokines including IL-1 $\beta$ are upregulated as a part of the immediate inflammatory responses to injury e.g. [6], cytokines are also upregulated in the spinal cord and brain [7]. An elevation of IL-6 level in the brainstem including the spinal trigeminal nucleus is found after trigeminal nerve injury in the rat [8]. Interleukin$1 \beta$ has been identified as a major inducer of cyclooxygenase$2(\mathrm{Cox}-2)$ in the CNS [9]. Interleukin- $1 \beta$ can directly activate nociceptors to generate action potentials and induce pain

*Address correspondence to this author Dept. of NPS, $650 \mathrm{~W}$. Baltimore St. Dental-8 South, Baltimore, MD 21201-1586, USA; Tel: (410) 706-3250; Fax: (410) 706-0865; E-mail: kren@umaryland.edu

${ }^{\#}$ These authors contributed equally to this work. hypersensitivity [10]. Intrathecally administered IL-1 $\beta$ produces enhanced dorsal horn nociceptive neuronal responses and behavioral hyperalgesia [11-13]. Intracerebroventricular injection of IL-1 $\beta$ has been shown to produce hyperalgesia in animals $[14,15]$. Pretreatment with the IL1 receptor antagonist (IL-1ra) completely abolished centrally IL-1 $\beta$-induced hyperalgesia [14]. Interestingly, hyperalgesia induced by an inflammatory irritant, lipopolysaccharide (LPS), is apparently mediated through an endogenous pain facilitatory pathway involving the rostral ventromedial medulla (RVM), a pivotal structure in descending pain modulation [16].

The subnuclei interpolaris/caudalis $(\mathrm{Vi} / \mathrm{Vc})$ transition zone of the spinal trigeminal complex is formed by the convergence of the rostral $\mathrm{Vc}$ and caudal $\mathrm{Vi}$ at the level of the obex. Studies have shown that the $\mathrm{Vi} / \mathrm{Vc}$ is a target site in addition to caudal subnucleus caudalis $(\mathrm{Vc})$, or medullary dorsal horn [17], for trigeminal pain processing [18-21]. $\mathrm{Vi} / \mathrm{Vc}$ neurons access brain regions concerned with important survival functions such as the response to stress and autonomic regulation, and pain modulation.

Associated with astroglial activation, IL- $1 \mathrm{~b}$ is upregulated in the $\mathrm{Vi} / \mathrm{Vc}$ transition zone after masseter muscle inflammation [5]. Further, IL-1b affects neuronal function through signal coupling with N-methyl-D-aspartate (NMDA) receptors in $\mathrm{Vi} / \mathrm{Vc}$. IL-1ra attenuated masseter hyperalgesia and inflammation-induced NMDA receptor 
phosphorylation [5]. Here we tested whether direct application of IL-1b into the $\mathrm{Vi} / \mathrm{Vc}$ transition zone could produce orofacial hyperalgesia. We focused on the ventral portion of the transition zone since this region exhibits unique responsiveness to orofacial injury and distinct connections with rostral and caudal structures [18-20, 22]. We show that a unilateral injection of IL-1b into the $\mathrm{Vi} / \mathrm{Vc}$ induced bilateral orofacial mechanical hyperalgesia that was mediated by NMDA receptors and that contralateral hyperalgesia requires a facilitatory drive from RVM.

\section{METHODS}

Male Sprague-Dawley rats were used (280-330 g, Harlan, Indianapolis). The experiments were approved by the Institutional Animal Care and Use Committee of the University of Maryland Dental School. For brain stem microinjection, a guide cannula $(\mathrm{C} 315 \mathrm{G}, 26$ gauge, Plastics One, Roanake, VA) was implanted under anesthesia with 50 $\mathrm{mg} / \mathrm{kg}$ pentobarbital sodium (i.p). Animals were securely placed into a stereotaxic device (Kopf Model 900). A burr hole was drilled and the guide cannula was lowered into the ventral $\mathrm{Vi} / \mathrm{Vc}$ transition zone by referring to the rat brain atlas [23]. In some experiments, a second guide cannula was placed in the RVM to inject ibotenic acid (IBO, $10 \mu \mathrm{g} / \mu \mathrm{l}, 0.2$ $\mu 1$, Sigma) to produce excitotoxic lesions [20]. The guide cannula was then secured with cranioplastic cement. To prevent clogging of the guide cannula, a dummy cannula (C315DC, Plastics One) was inserted and secured in place until the time of injection. The wound was cleaned with an antiseptic solution and closed with 4-0 silk sutures. Animals were allowed to recover for 1 week before further experimentation. A group of rats received injection of an inflammatory agent, complete Freund's adjuvant (CFA, 0.05 $\mathrm{ml}, 1: 1 \mathrm{oil} / \mathrm{saline})$, into the masseter muscle to produce inflammation and hyperalgesia as described elsewhere [5]. Drugs were injected into the ventral $\mathrm{Vi} / \mathrm{Vc}$ transition zone through a 33-gauge injection cannula (C315I, Plastic One) inserted through the tip of the guide cannula. The injection cannula was connected to a $1-\mu$ l Hamilton syringe by a polyethylene-10 tubing. All injections $(0.5 \mu 1)$ were performed by delivering drug or vehicle solutions slowly over a 2-min period. MK-801, AP-5, fluorocitrate, minocycline and propentofylline were purchased from Sigma (St. Louis, MO). Recombinant rat IL-1 $\beta$ was from PeproTech, (Rocky Hill, NJ) and IL-1ra (kineret) from Amgen (Thousand Oaks, CA). Animals were perfused with $4 \%$ paraformaldehyde at the conclusion of the experiment and the sections of brain stem tissues were stained with cresyl violet for histological verification of the sites of injection in the Vi/Vc (Fig. 1A) and RVM (Fig. 4A).

Behavioral tests were conducted under blind conditions as described elsewhere $[20,24]$. A series of calibrated von Frey filaments were applied to the facial site above the masseter muscle. An active withdrawal of the head from the probing filament was defined as a response. Each von Frey filament was applied 5 times at intervals of a few sec. The response frequencies [(number of responses/number of stimuli) X100\%] to a range of von Frey filament forces were determined and a stimulus-response (S-R) curve plotted. After a non-linear regression analysis (GraphPad Prism), an $\mathrm{EF}_{50}$ value, defined as the von Frey filament force $(\mathrm{g})$ that produces a $50 \%$ response frequency, was derived from the $\mathrm{S}$ -
$\mathrm{R}$ curve. We used $\mathrm{EF}_{50}$ values as a measure of mechanical sensitivity. A leftward shift of the S-R curve, resulting in a reduction of $\mathrm{EF}_{50}$, occurred after inflammation $[20,25]$. This shift of the curve suggests the presence of mechanical hyperalgesia and allodynia since there was an increase in response to suprathreshold stimuli and a decreased response threshold for nocifensive behavior. Data are presented as mean \pm S.E.M. Statistical comparisons were made by ANOVA with repeated measures and post hoc comparisons (Newman-Keuls). $\mathrm{P} \leq 0.05$ is considered significant.

\section{RESULTS}

\section{Injection of IL-1 $\beta$ into the Vi/Ve Transition Zone Produced Orofacial Hyperalgesia}

The mechanical responses to von Frey filament probing were assessed and stimulus-response frequency curves generated. After injection of IL-1 $\beta$ (1.6-160 fmol, or 27.7 pg-2.8 ng, $\mathrm{n}=6$ ) into the $\mathrm{Vi} / \mathrm{Vc}$ transition zone, there was a leftward shift of the stimulus-response frequency curve (Fig. 1B). Consistently, there were significant decreases in $\mathrm{EF}_{50}$ values at the testing site (Fig. 1C,D), indicating the occurrence of orofacial hyperalgesia. Compared to baseline responses and saline controls, the hyperalgesia was detectable as early as 30 min after IL- $1 \beta$ injection and lasted for 2-6 hours. The effect of IL-1 $\beta$ on $\mathrm{EF}_{50}$ values was dosedependent. The lowest dose $(0.016 \mathrm{fmol})$ did not produce an effect (not shown) and the highest dose (160 fmol) produced the most intense hyperalgesia (Fig. 1C). Interestingly, the hyperalgesia developed bilaterally after a unilateral injection of IL- $1 \beta$ into the $\mathrm{Vi} / \mathrm{Vc}$ region (Fig. 1C,D).

\section{IL-1 $\beta$-Induced Hyperalgesia was Reversed by IL-1 Receptor and NMDA Receptor Antagonists}

Intra-Vi/Vc pretreatment with IL-1ra $(1 \mathrm{nmol}, \mathrm{n}=4)$ at 10 min prior to IL-1 $\beta$ injection completely blocked the IL-1 $\beta$ induced hyperalgesia $(n=4, p<0.01)$ (Fig. 2A), confirming that the effect was mediated through the IL-1 receptor. We have shown previously that IL-1R signaling was linked to NMDA receptor activation in the $\mathrm{Vi} / \mathrm{Vc}$ transition zone [5]. We then tested whether the IL-1 $\beta$-induced hyperalgesia involved NMDA receptors. Pre-injection of AP-5 (10 pmol, $\mathrm{n}=4$ ) (Fig. 2B), a competitive NMDA receptor antagonist, and MK-801 (20 pmol, n=4) (Fig. 2C), an NMDA receptor channel blocker, significantly blocked IL-1 $\beta$-induced orofacial hyperalgesia $(p<0.01)$, suggesting the involvement of NMDA receptors.

\section{Effect of Glial Inhibitors}

We then tested whether glial activity is involved in IL$1 \beta$-induced orofacial hyperalgesia. Intra- $\mathrm{Vi} / \mathrm{Vc}$ pretreatment with fluorocitrate (120 pmol, $\mathrm{n}=4)$, a metabolic gliotoxin, and minocycline (200 pmol, $\mathrm{n}=4)$, an inhibitor of microglia, did not attenuate IL-1 $\beta$-induced orofacial hyperalgesia (Fig. 3). Since fluorocitrate is relatively selective against astroglia [26] and minocycline is selective against microglia [27], application of either of these two agents alone may be insufficient to block both microglial and astroglial activity. Therefore, we tested the effects of a non-selective glial inhibitor/modulator, propentofylline. Pretreatment with propentofylline at a dose that was antihyperalgesic [28] (10 pmol, $n=6$ ) did not affect IL-1 $\beta$-induced hyperalgesia (Fig. 3C). These results suggest direct application of IL-1 $\beta$ 

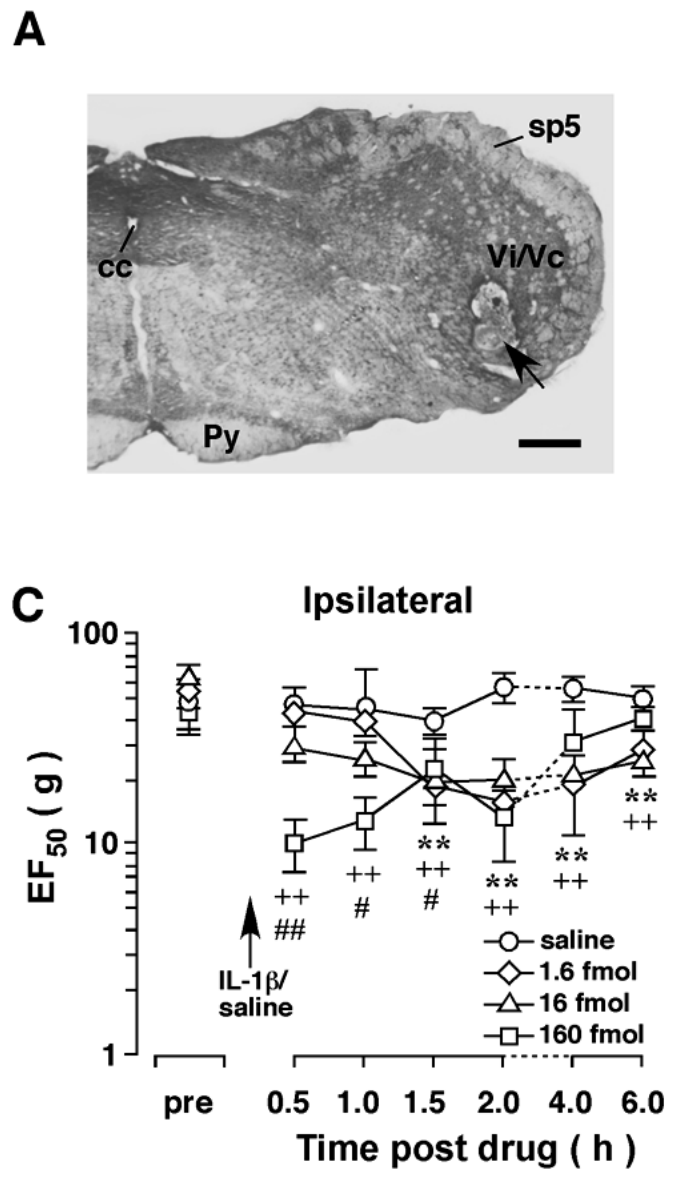

B
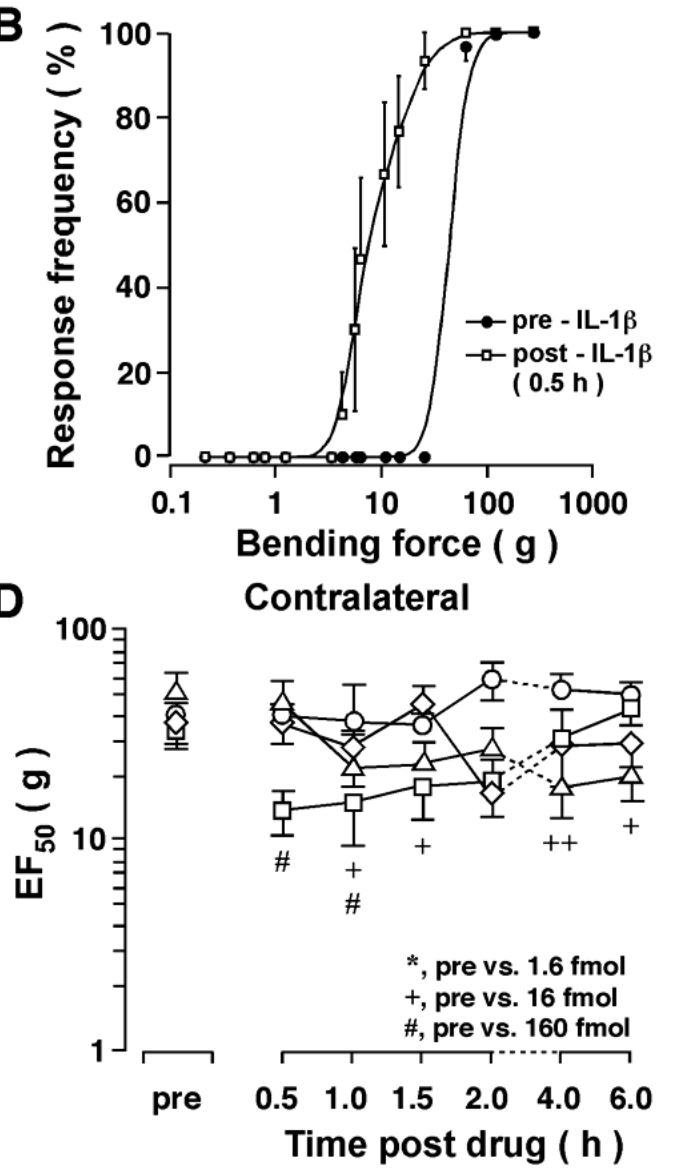

Fig. (1). Mechanical hyperalgesia/allodynia induced by injection of IL-1 $\beta$ into the Vi/Vc transition zone of the rat. A. An example of caudal brain stem section stained with cresyl violet for histological verification of the site of microinjection. Arrow indicates the injection site in ventral Vi/Vc. Scale bar $=500 \mu \mathrm{m}$. cc, central canal; Py, pyramidal tract; sp5, spinal trigeminal tract; Vi/Vc, trigeminal subnuclei interpolaris/caudalis transition zone. B. Stimulus-response function curves illustrating the intensity-dependent head withdrawal responses to mechanical stimuli. Each curve was established with a series of subthreshold to suprathreshold range of von Frey filament forces and the response frequency is plotted against the stimulus intensity. IL-1 $\beta$ (160 fmol) was injected into the ventral Vi/Vc. The skin site above the masseter muscle was probed. Note that there was a leftward shift of the curve at $30 \mathrm{~min}$ after IL-1 $\beta$ injection compared to the pre-IL-1 $\beta$ curve $(\mathrm{p}<0.01)$, suggesting the development of mechanical hyperalgesia and allodynia. Best-fit curves were generated by nonlinear regression analysis (GraphPad Prism). C, D. The $\mathrm{EF}_{50} \mathrm{~s}$ were derived from the respective stimulus-response frequency function curves and are plotted against time. Note significant decreases in $\mathrm{EF}_{50} \mathrm{~s}$ at $30 \mathrm{~min}-6 \mathrm{~h}$ after IL-1 $\beta$ injection, indicating IL-1 $\tilde{\beta}$ induced bilateral hyperalgesia/allodynia. $+, \#: \mathrm{p}<0.05 ; * *,++, \# \#: \mathrm{p}<0.01$ (ANOVA with repeated measures and post-hoc test). Dashed lines indicate interruption of the linearity of the time scale.

produced effects that were downstream of glial cell activity to facilitate neuronal activity and produce hyperalgesia.

\section{The Effect of RVM Lesions on IL-1 $\beta$-Induced Hyperalgesia}

The results indicate that a unilateral injection of IL-1 $\beta$ into the $\mathrm{Vi} / \mathrm{Vc}$ transition zone produced bilateral hyperalgesia at the orofacial site. We have shown previously that there are reciprocal facilitatory interactions between $\mathrm{Vi} / \mathrm{Vc}$ and RVM pain modulatory circuitry [20]. Thus, we tested the hypothesis that IL-1 $\beta$-induced behavioral hyperalgesia was dependent on RVM and $\mathrm{Vi} / \mathrm{Vc}$ interactions. To evaluate the role of RVM descending input in orofacial hyperalgesia, a soma-selective neurotoxin IBO was microinjected into the RVM to produce focal neural lesions and its effect on IL-1 $\beta$-induced hyperalgesia was assessed.
Ibotenic acid $(2 \mu \mathrm{g} / 0.2 \mu \mathrm{l})$ was microinjected into the RVM $(n=5)$. Saline $(0.2 \mu l)$ was injected as a vehicle control $(n=6)$. The lesions were localized in RVM, mainly in nucleus raphe magnus (NRM) and the alpha part of the gigantocellular reticular nucleus (Gi $\alpha$ ) (Fig. 4A). In rats receiving ibotenic acid injections, the IL-1 $\beta$-induced hyperalgesia was abolished on the contralateral site as compared to salinetreated rats $(p<0.01-0.001$, IBO vs. saline) (Fig. 4B). Interestingly, on the ipsilateral site, there was a trend of further reduction of $\mathrm{EF}_{50} \mathrm{~S}$ and the decease reached statistical significance at $4.5-5 \mathrm{~h}$ in IBO-treated rats $(\mathrm{p}<0.01-0.001$, vs. saline) (Fig. 4C), suggesting that the IL- $1 \beta$-induced mechanical hyperalgesia was further enhanced.

\section{DISCUSSION}

Our recent studies indicate that the prototypic proinflammatory cytokine IL-1 $\beta$ is upregulated in glial cells in the spinal trigeminal complex and that IL-1 receptor 

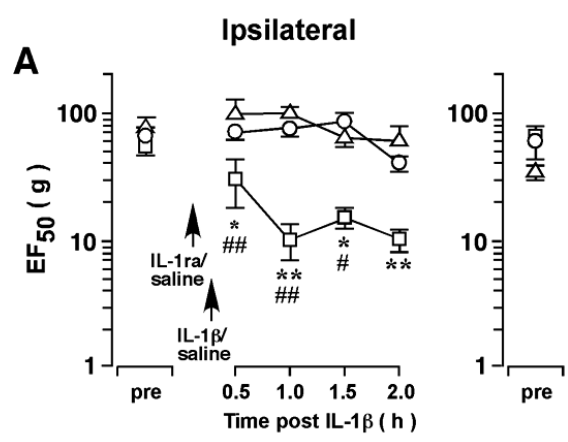

\section{Contralateral}
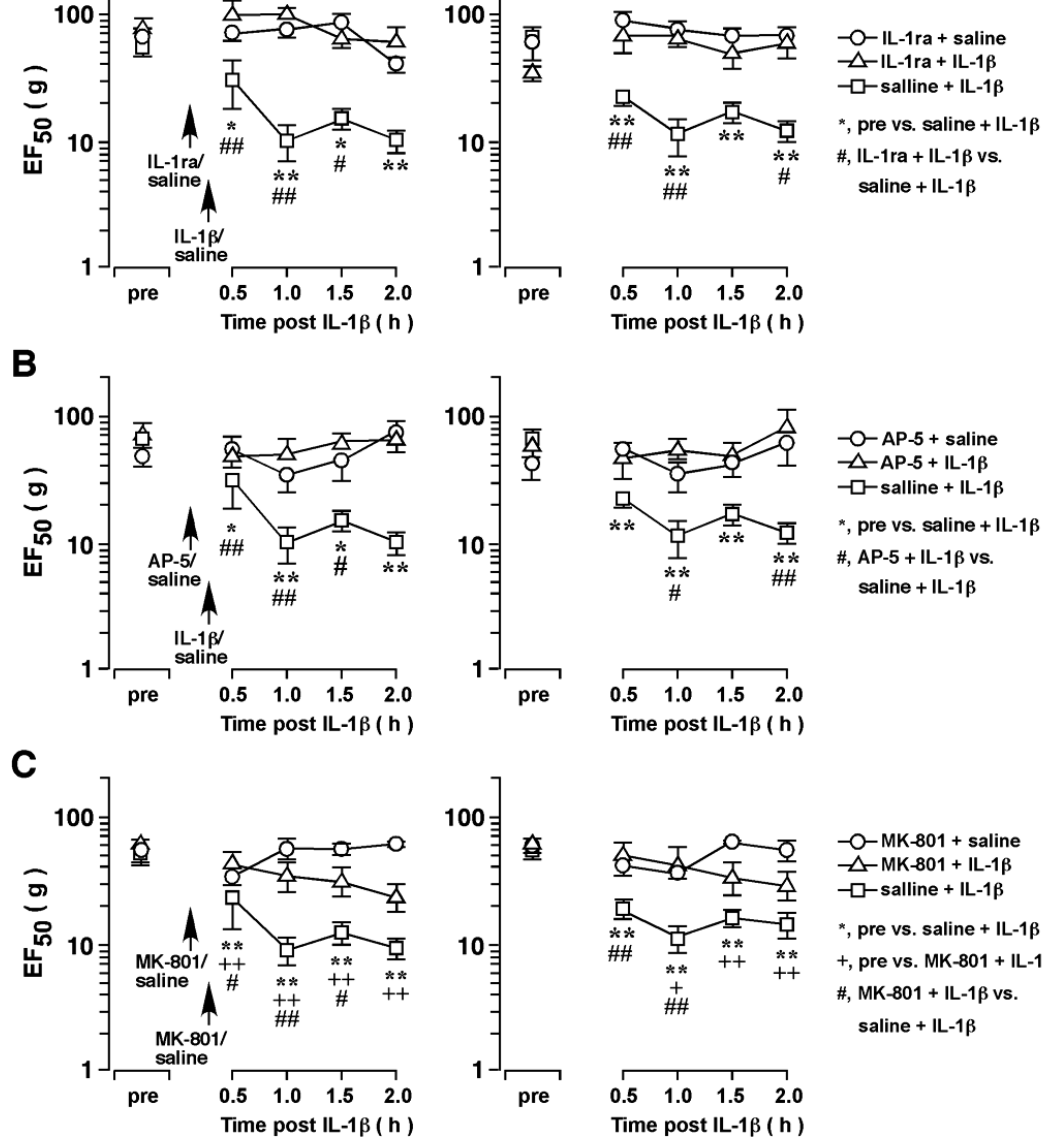

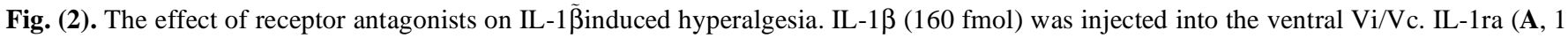
$\mathrm{nmol})$, AP-5 (B, $10 \mathrm{pmol})$ and MK-801 (C, $20 \mathrm{pmol})$ was injected into the ventral Vi/Vc at 10 min prior to IL-1 $\beta$ injection. Pretreatment with IL-1ra, AP-5 and MK-801 prevented or attenuated IL-1 $\beta$-induced hyperalgesia as compared to saline-pretreated rats. *, +, \#: p<0.05; **, ++, \#\#: $\mathrm{p}<0.01$ (ANOVA with repeated measures and post-hoc test).

signaling interacts with NMDA receptors to facilitate central sensitization and orofacial hyperalgesia [5]. The present experiments extend previous results by showing that direct administration of IL- $1 \beta$ into the ventral trigeminal transition zone produced orofacial hyperalgesia that lasted for hours. The IL-1 $\beta$-induced hyperalgesia appeared to be downstream to glial activity and involved activation of NMDA receptors. Further, unilateral injection of IL-1 $\beta$ also led to contralateral hyperalgesia that was dependent on RVM descending circuitry. These results support the view that the cytokine cascade is an important contributor to the development of persistent pain states $[9,29]$. The present results are also consistent with previous observations that the $\mathrm{Vi} / \mathrm{Vc}$ region is involved in trigeminal pain processing and orofacial hyperalgesia [21].

Proinflammatory cytokines and their receptors exist in the brain $[30,31]$. The IL-1 $\beta$ receptor is expressed in intrinsic dorsal horn as well as trigeminal neurons $[5,9]$. Interleukin-1 $\beta$ protein expression is increased in the superficial layer of the dorsal horn and cell nuclei of the ventral horn in nerve-injured rats when compared to sham operated rats [32]. Interleukin-1 $\beta$ has been identified as a major inducer of cyclooxygenase- 2 in the CNS [9]. The activation of cyclooxygenase- 2 leads to central prostanoid production and may, in part, mediate CNS neuronal hyperactivity after muscle and joint inflammation.

Central nervous system cytokines can be released from glia to influence or modulate neuronal function [33]. Our previous results show that IL-1 $\beta$ is selectively induced in astroglia in $\mathrm{Vi} / \mathrm{Vc}$ after inflammation of the masseter muscle in rats and that IL-1 receptors colocalize with the NR1 subunit of the NMDA receptor in trigeminal neurons [5]. These results suggest that IL-1 $\beta$ may be released from astroglia and modulate NMDA receptor-induced neuronal hyperexcitability. In the present study, pretreatment with glial inhibitors did not block IL-1 $\beta$-induced hyperalgesia even with relatively high doses that have been shown to be effective in attenuating hyperalgesia after injury [5, 28]. Although the glial inhibitor/modulator propentofylline did not block IL-1 $\beta$-induced hyperalgesia, propentofylline was able to attenuate hyperalgesia after masseter inflammation (unpublished observations). Likewise, fluorocitrate was unable to block IL-1 $\beta$-induced NMDA receptor phosphorylation in the $\mathrm{Vi} / \mathrm{Vc}$ transition zone in vitro, but attenuated masseter inflammatory hyperalgesia [5]. Collectively, these results suggest that the IL-1 $\beta$-produced 

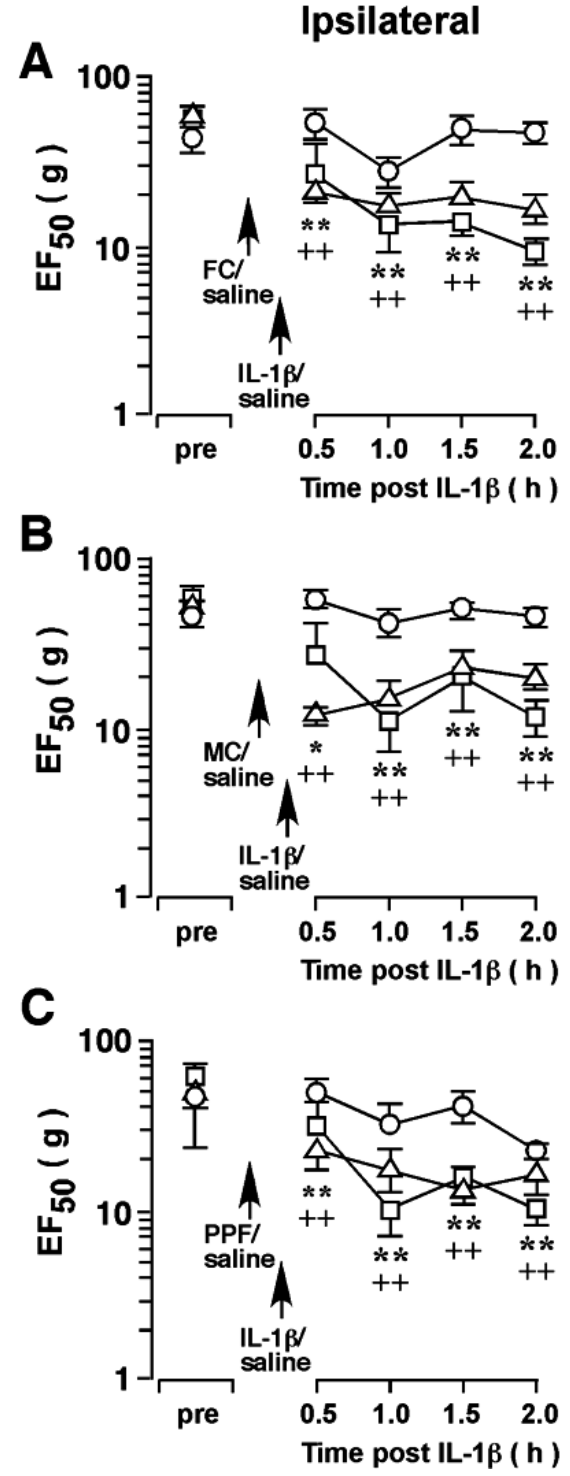

Contralateral
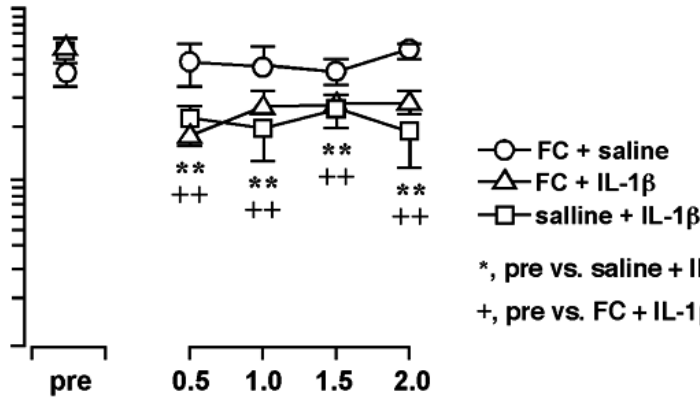

*, pre vs. saline + IL-1 $\beta$

+ , pre vs. FC + IL-1 $\beta$
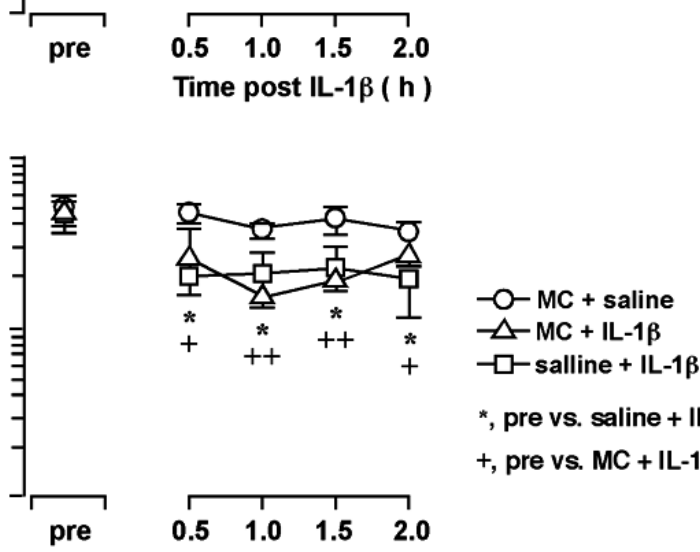

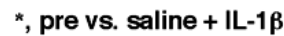

+ , pre vs. $M C+I L-1 \beta$
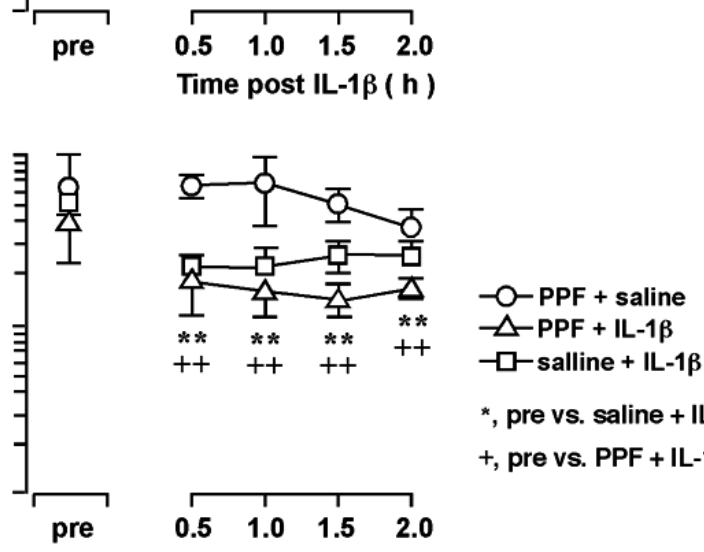

*, pre vs. saline + IL-1及

+ , pre vs. PPF + IL-1 $\beta$

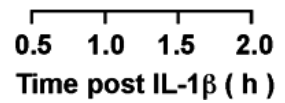

Fig. (3). The effect of glial inhibitors on IL-1 $\beta$-induced orofacial hyperalgesia. IL-1 $\beta$ (160 fmol) was injected into the ventral Vi/Vc. Fluorocitrate (A) (FC, $120 \mathrm{pmol})$, minocycline (B) (MC, $200 \mathrm{pmol})$, and propentofylline (C) (PPF, 10 pmol) was injected into the ventral $\mathrm{Vi} / \mathrm{Vc}$ at $10 \mathrm{~min}$ prior to IL-1 $\beta$ injection. Pretreatment with fluorocitrate, minocycline and propentofylline did not prevent IL-1 $\beta$-induced hyperalgesia. *, +: p<0.05; **, ++: $\mathrm{p}<0.01$ (ANOVA with repeated measures and post-hoc test).

effect on nociception is through a direct action on neurons and downstream to glial activity. Direct application of IL-1 $\beta$ bypasses glial cells to produce neuronal hyperexcitability and hyperalgesia.

NMDA receptors play a major role in central sensitization and pain hypersensitivity [34, 35], including orofacial hyperalgesia [5, 36-38]. Ma et al. [39] show that IL-1 $\beta$ exaggerates NMDA and glutamate-evoked hippocampal neuron death in the rat. Most interestingly, the IL-1 $\beta$ signaling may facilitate NMDA receptor activation in neurons [5, 40-42]. The present results provide behavioral evidence that NMDA receptor activity is necessary for IL$1 \beta$-induced central neuronal hyperexcitability and hyperalgesia. Consistently, IL-1R colocalized with NMDA receptor subunits in $\mathrm{Vi} / \mathrm{Vc}$ neurons and IL- $1 \beta$ induced an enhanced NMDA receptor phosphorylation via IL-1R signaling and intracellular biochemical pathways involving phospholipases, protein kinase $\mathrm{C}$ and intracellular calcium release [5]. Both IL-1 $\beta$-induced NMDA receptor phosphorylation and behavioral hyperalgesia occurred rapidly within $30 \mathrm{~min}$ after application [5]. Our behavioral results support the hypothesis that glial activation, inflammatory cytokine release and NMDA receptor activation are sequential events in the nervous system responses to injury and that IL-1 $\beta$ and its interaction with NMDA receptors plays a critical role in the central mechanisms of hyperalgesia.

An interesting finding in the present study is that a unilateral injection of IL-1 $\beta$ induced hyperalgesia bilaterally. This result may be explained by the finding that there are reciprocal connections between the trigeminal transition zone and RVM, a key midline structure in descending pain facilitation and inhibition [20]. The descending effects from RVM occurred at multiple targets (inflamed hind paw, non- 
A
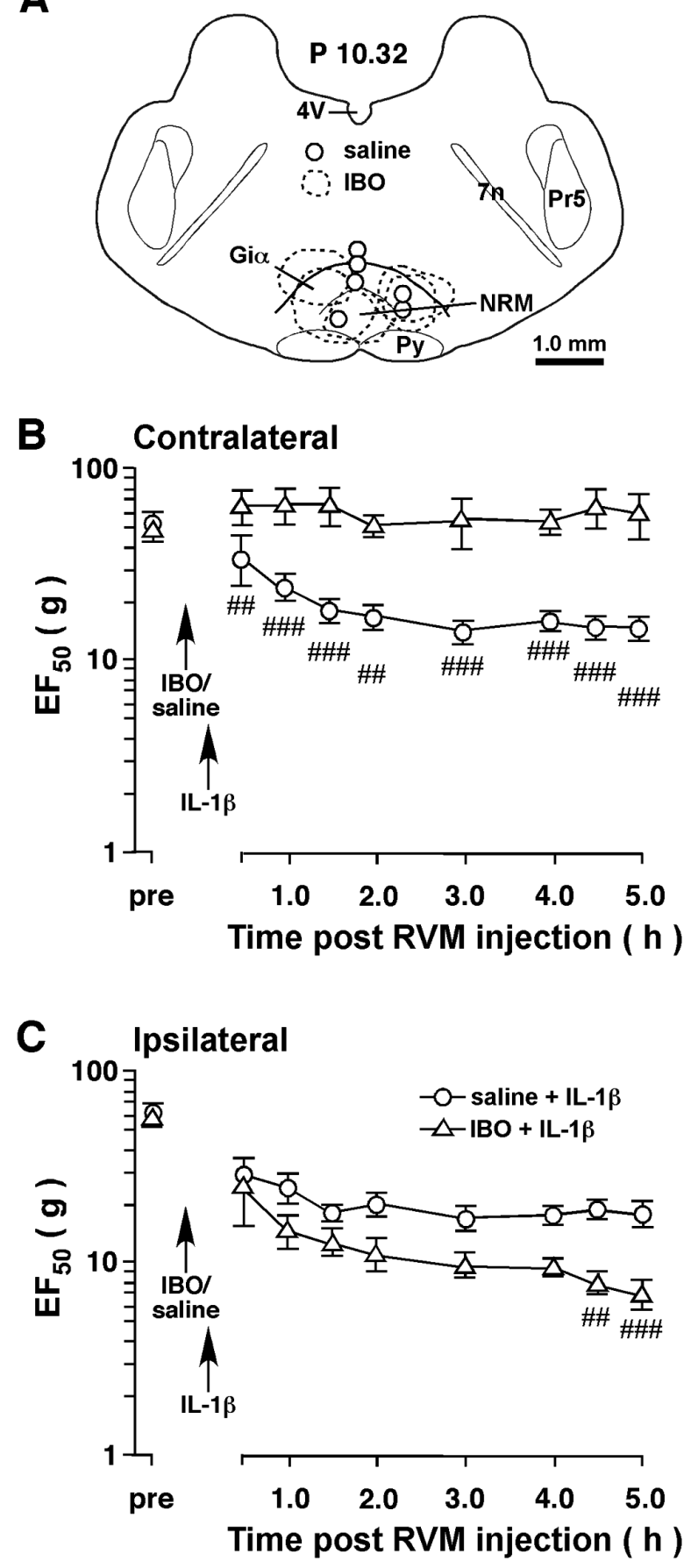

Fig. (4). Intra-RVM ibotenic acid (IBO) attenuated IL-1 $\beta$-induced contralateral hyperalgesia. Ten-min before a unilateral injection of IL-1 $\beta$ into the $\mathrm{Vi} / \mathrm{Vc}$ transition zone, IBO $(2 \mu \mathrm{g} / 0.2 \mu \mathrm{l}, \mathrm{n}=5)$ was microinjected into the RVM to produce excitotoxic neuronal lesions in RVM. Saline was injected as a vehicle control. A. Schematic illustration of the microinjection sites and IBO-produced lesions. The extent of IBOproduced lesions is shown as dashed enclosures. The open circles indicate the injection sites for saline. B. Compared to saline-injected rats, RVM excitotoxic lesions prevented the development of contralateral hyperalgesia after injection of IL-1 $\beta$ into the Vi/Vc transition zone. C. Compared to saline control, there was a slight further decrease in $\mathrm{EF}_{50} \mathrm{~s}$ on the ipsilateral site in the IBO-treated rats. \#\#, $\mathrm{p}<0.01$, \#\#\#, $\mathrm{p}<0.001$, saline vs. IBO (ANOVA with repeated measures and post-hoc test).

inflamed hind paw, and tail) [43]. Thus, descending pain modulation exhibits diffuse effects and weak somatotopy. $\mathrm{Vi} / \mathrm{Vc}$ neurons may relay input to RVM, which in turn produces contralateral net descending facilitation and behavioral hyperalgesia. Supporting this hypothesis, excitotoxic lesions of RVM neurons abolished IL-1 $\beta$ - induced contralateral hyperalgesia. Consistently, lesions of RVM significantly attenuate contralateral orofacial hyperalgesia after masseter inflammation [20].

It is surprising that intra-Vi/Vc IL-1 $\beta$-induced ipsilateral orofacial hyperalgesia was not attenuated but rather slightly enhanced after excitotoxic lesions of RVM, which suggests 
that IL-1 $\beta$-induced ipsilateral hyperexcitability was not dependent on a descending facilitatory drive. This result is apparently different from the model of masseter muscle inflammation, in which RVM lesions abolished ipsilateral hyperalgesia at 1-3 d after inflammation [20]. It is noted that the present model produces relatively short lasting hyperalgesia when compared to masseter muscle inflammation and that the effect of RVM lesions was tested in the persistent phase of hyperalgesia in previous studies [20]. It is likely that persistent inflammation-induced hyperalgesia is maintained by descending facilitatory drive. The lack of an effect of RVM lesions on IL-1 $\beta$-induced ipsilateral hyperalgesia may also be explained by a removal of a descending net inhibitory effect on the ipsilateral side after IL-1 $\beta$ injection. It has been shown that there are dynamic changes in descending pain modulation after inflammation of the rat hind paw, which involves an ipsilateral enhanced inhibition [44, 45]. These results also suggest differential descending control of primary and secondary hyperalgesia. While there is a dynamic balance between descending inhibition and facilitation on primary hyperalgesia, the descending modulation of secondary hyperalgesia may be predominantly facilitatory [46, 47]. We propose that similar unilateral activation of IL-1 $\beta$ at the level of the spinal and medullary dorsal horns may contribute to contralateral descending pain facilitation after injury.

\section{ACKNOWLEDGEMENTS}

We thank Ms. S. Zou for technical assistance. This work was supported by National Institutes of Health grants DE11964, DE018573, NS060735, NS059028. B.C. is supported by T32 DE007309.

\section{REFERENCES}

[1] Watkins LR, Maier SF. Immune regulation of central nervous system functions: from sickness responses to pathological pain. J Intern Med 2005; 257: 139-55.

[2] Dinarello CA. Therapeutic strategies to reduce IL-1 activity in treating local and systemic inflammation. Curr Opin Pharmacol 2004; 4: 378-85

[3] Kawasaki Y, Xu ZZ, Wang X, et al. Distinct roles of matrix metalloproteases in the early- and late-phase development of neuropathic pain. Nat Med 2008; 14: 331-6.

[4] Ren K, Torres R. Role of interleukin-1beta during pain and inflammation. Brain Res Rev 2009; 60: 57-64.

[5] Guo W, Wang H, Watanabe M, et al. Glial-cytokine-neuronal interactions underlying the mechanisms of persistent pain. J Neurosci 2007; 27: 6006-18.

[6] Watanabe M, Guo W, Zou S-P, Sugiyo S, Dubner R, Ren K. Antibody array analysis of peripheral and blood cytokine levels in rats after masseter inflammation. Neurosci Lett 2005; 382: 128-33.

[7] Raghavendra V, Tanga FY, DeLeo JA. Complete Freunds adjuvant-induced peripheral inflammation evokes glial activation and proinflammatory cytokine expression in the CNS. Eur $\mathbf{J}$ Neurosci 2004; 20: 467-73.

[8] Anderson LC, Rao RD. Interleukin-6 and nerve growth factor levels in peripheral nerve and brainstem after trigeminal nerve injury in the rat. Arch Oral Biol 2001; 46: 633-40.

[9] Samad TA, Moore KA, Sapirstein A, et al. Interleukin-1betamediated induction of Cox-2 in the CNS contributes to inflammatory pain hypersensitivity. Nature 2001; 410: 471-5.

[10] Binshtok AM, Wang H, Zimmermann K, et al. Nociceptors are interleukin-1beta sensors. J Neurosci 2008; 28: 14062-73.

[11] Reeve AJ, Patel S, Fox A, Walker K, Urban L. Intrathecally administered endotoxin or cytokines produce allodynia, hyperalgesia and changes in spinal cord neuronal responses to nociceptive stimuli in the rat. Eur J Pain 2000; 4: 247-57.
[12] Falchi M, Ferrara F, Gharib C, Dib B. Hyperalgesic effect of intrathecally administered interleukin-1 in rats. Drugs Exp Clin Res 2001; 27: 97-101.

[13] Sung CS, Wen ZH, Chang WK, et al. Inhibition of p38 mitogenactivated protein kinase attenuates interleukin-1beta-induced thermal hyperalgesia and inducible nitric oxide synthase expression in the spinal cord. J Neurochem 2005; 94: 742-52.

[14] Oka T, Aou S, Hori T. Intracerebroventricular injection of interleukin-1beta induces hyperalgesia in rats. Brain Res 1993; 624: 61-8.

[15] Watkins LR, Wiertelak EP, Goehler LE, Smith KP, Martin D, Maier SF. Characterization of cytokine-induced hyperalgesia. Brain Res 1994; 654: 15-26.

[16] Wiertelak EP, Roemer B, Maier SF, Watkins LR. Comparison of the effects of nucleus tractus solitarius and ventral medial medulla lesions on illness-induced and subcutaneous formalin-induced hyperalgesias. Brain Res 1997; 748: 143-50.

[17] Xie YF, Zhang S, Chiang CY, Hu JW, Dostrovsky JO, Sessle BJ. Involvement of glia in central sensitization in trigeminal subnucleus caudalis (medullary dorsal horn). Brain Behav Immun 2007; 21: 634-41.

[18] Strassman AM, Vos BP. Somatotopic and laminar organization of Fos-like immunoreactivity in the medullary and upper cervical dorsal horn induced by noxious facial stimulation in the rat. $\mathrm{J}$ Comp Neurol 1993; 331: 495-516.

[19] Ikeda T, Terayama R, Jue S-S, Sugiyo S, Dubner R, Ren K. Differential rostral projections of caudal brainstem neurons receiving trigeminal input after masseter inflammation. J Comp Neurol 2003; 465: 220-33.

[20] Sugiyo S, Takemura M, Dubner R, Ren K. Trigeminal transition zone/rostral ventromedial medulla connections and facilitation of orofacial hyperalgesia after masseter inflammation in rats. J Comp Neurol 2005; 493: 510-23.

[21] Dubner R, Ren K. Persistent orofacial pain. In: Laskin DM, Greene CS, Hylander WL, Eds. Temporomandibular disorders: an evidence-based approach to diagnosis and treatment. Chicago: Quintessence Publishing Co, Inc 2006; pp. 89-97.

[22] Bereiter DA, Hirata H, Hu JW. Trigeminal subnucleus caudalis: beyond homologies with the spinal dorsal horn. Pain 2000; 88: 221-4.

[23] Paxinos G, Watson C. The rat brain in stereotaxic coordinates. 5th ed. Amsterdam: Elsevier 2005.

[24] Ren K. An improved method for assessing mechanical allodynia in the rat. Physiol Behav 1999; 67: 711-6.

[25] Guo W, Wei F, Zou S, et al. Group I metabotropic glutamate receptor NMDA receptor coupling and signaling cascade mediate spinal dorsal horn NMDA receptor $2 \mathrm{~B}$ tyrosine phosphorylation associated with inflammatory hyperalgesia. J Neurosci 2004; 24: 9161-73.

[26] Hosoi R, Okada M, Hatazawa J, Gee A, Inoue O. Effect of astrocytic energy metabolism depressant on $14 \mathrm{C}$-acetate uptake in intact rat brain. J Cereb Blood Flow Metab 2004; 24: 188-90.

[27] Tikka T, Fiebich BL, Goldsteins G, Keinanen R, Koistinaho J. Minocycline, a tetracycline derivative, is neuroprotective against excitotoxicity by inhibiting activation and proliferation of microglia. J Neurosci 2001; 21: 2580-8.

[28] Wei F, Guo W, Zou S, Ren K, Dubner R. Supraspinal glialneuronal interactions contribute to descending pain facilitation. J Neurosci 2008; 28: 10482-95.

[29] Watkins LR, Maier SF, Goehler LE. Immune activation: the role of pro-inflammatory cytokines in inflammation, illness responses and pathological pain states. Pain 1995; 63: 289-302.

[30] Hopkins SJ, Rothwell NJ. Cytokines and the nervous system I: Expression and recognition. Trends Neurosci 1995; 18: 83-8.

[31] Schobitz B, De Kloet ER, Holsboer F. Gene expression and function of interleukin 1, interleukin 6 and tumor necrosis factor in the brain. Prog Neurobiol 1994; 44: 397-432.

[32] Hashizume H, DeLeo JA, Colburn RW, Weinstein JN. Spinal glial activation and cytokine expression after lumbar root injury in the rat. Spine 2000; 25: 1206-17.

[33] Srinivasan D, Yen JH, Joseph DJ, Friedman W. Cell type-specific interleukin-1beta signaling in the CNS. J Neurosci 2004; 24: 64828.

[34] Woolf CJ, Thompson SW. The induction and maintenance of central sensitization is dependent on N-methyl-D-aspartic acid 
receptor activation; implications for the treatment of post-injury pain hypersensitivity states. Pain 1991; 44: 293-9.

[35] Ren K, Hylden JL, Williams GM, Ruda MA, Dubner R. The effects of a non-competitive NMDA receptor antagonist, MK-801, on behavioral hyperalgesia and dorsal horn neuronal activity in rats with unilateral inflammation. Pain 1992; 50: 331-44.

[36] Chiang CY, Hu JW, Sessle BJ. NMDA receptor involvement in neuroplastic changes induced by neonatal capsaicin treatment in trigeminal nociceptive neurons. J Neurophysiol 1997; 78: 2799803.

[37] Bereiter DA, Bereiter DF. Morphine and NMDA receptor antagonism reduce c-fos expression in spinal trigeminal nucleus produced by acute injury to the TMJ region. Pain 2000; 85: 65-77.

[38] Wang S, Lim G, Mao J, Sung B, Mao J. Regulation of the trigeminal NR1 subunit expression induced by inflammation of the temporomandibular joint region in rats. Pain 2009; 141: 97-103.

[39] Ma XC, Gottschall PE, Chen LT, Wiranowska M, Phelps CP. Role and mechanisms of interleukin-1 in the modulation of neurotoxicity. Neuroimmunomodulation 2002-2003; 10: 199-207.

[40] Viviani B, Bartesaghi S, Gardoni F, et al. Interleukin-1beta enhances NMDA receptor-mediated intracellular calcium increase through activation of the Src family of kinases. J Neurosci 2003; 23: $8692-700$
[41] Yang S, Liu ZW, Wen L, Qiao HF, Zhou WX, Zhang YX. Interleukin-1beta enhances NMDA receptor-mediated current but inhibits excitatory synaptic transmission. Brain Res 2005; 1034: 172-9.

[42] Zhang R, Yamada J, Hayashi Y, Wu Z, Koyama S, Nakanishi H. Inhibition of NMDA-induced outward currents by interleukin-1beta in hippocampal neurons. Biochem Biophys Res Commun 2008; 372: 816-20.

[43] Guan Y, Terayama R, Dubner R, Ren K. Plasticity in excitatory amino acid receptor-mediated descending pain modulation after inflammation. J Pharmacol Exp Ther 2002; 300: 513-20.

[44] Ren K, Dubner R. Enhanced descending modulation of nociception in rats with persistent hindpaw inflammation. J Neurophysiol 1996 76: 3025-37.

[45] Terayama R, Guan Y, Dubner R, Ren K. Activity-induced plasticity in brain stem pain modulatory circuitry after inflammation. Neuroreport 2000; 11: 1915-9.

[46] Ren K, Dubner R. Descending modulation in persistent pain: an update. Pain 2002; 100: 1-6.

[47] Vanegas H, Schaible H-G. Descending control of persistent pain: inhibitory or facilitatory? Brain Res Rev 2004; 46: 295-309.

(C) Shimizu et al.; Licensee Bentham Open.

This is an open access article licensed under the terms of the Creative Commons Attribution Non-Commercial License (http://creativecommons.org/licenses/by-nc/3.0/) which permits unrestricted, non-commercial use, distribution and reproduction in any medium, provided the work is properly cited. 